\title{
Professor Fabio Augusto, a pioneer researcher in Brazil in the development of modern analytical separation techniques, discussed with BrJAC his memories and lucid ideas
about the situation of science
in the country
}

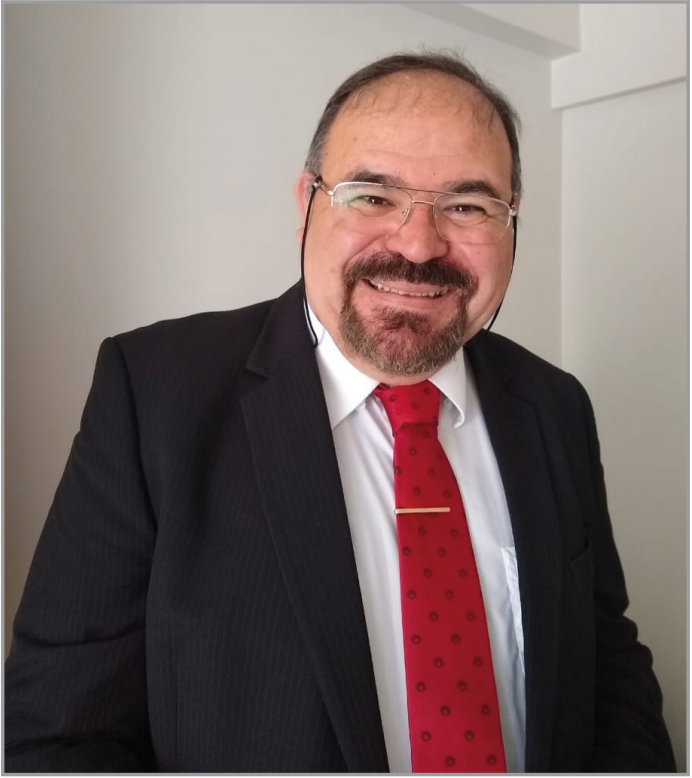

Fabio Augusto (1D)

Full Professor

Department of Analytical Chemistry, Institute of Chemistry University of Campinas, Campinas, SP, Brazil

Prof. Dr. Fabio Augusto graduated from the Institute of Chemistry at the University of Campinas (IQ-Unicamp) in 1986 with a degree in chemistry. Before that, in 1982, he was a trainee at Rhodia S.A. Chemical Unit in Santo André, SP, Brazil, where he took the first steps in the area of chromatography. In 1990, he became a Master in Chemistry, and in 1996 a Doctor in Sciences, both from IQ-Unicamp. In 1996, Fabio Augusto, along with Antonio Luiz Pires Valente, professor at IQ-Unicamp, founded the "Laboratório de Cromatografia Gasosa-LCG," which was the pioneer chromatography laboratory in important fields of analytical chemistry in Latin America, developing methods and technologies for solid-phase microextraction (SPME) and comprehensive two-dimensional gas chromatography (GCxGC). In 2005, Fabio Augusto presented his free-docency thesis with the monograph entitled "Solid Phase Microextraction SPME" at IQ-Unicamp.

It was Fabio Augusto's experience at Rhodia as a trainee that gave him direction for his professional career. At Rhodia, he worked with chromatographs made in Brazil by "CG Instrumentos Científicos", a company founded by Remolo Ciola, a professor at the Institute of ChemistryUniversity of Sao Paulo, SP, Brazil, who died in 2010. After 37 years of work in chromatography, Fabio Augusto received the "Ciola Medal" in recognition of his dedication to the development and dissemination of chromatography in Brazil and for his excellent contributions to science. The Ciola Medal was awarded to Fabio Augusto at the XVII Latin American Symposium on Chromatography and Related Techniques (COLACRO) in 2019.

Fabio Augusto has previously received the following awards and recognitions:

- "Genzo Shimadzu" in $\mathbf{2 0 1 8}$ for the best poster at the $\mathbf{4 2}{ }^{\text {nd }}$ International Symposium on Capillary Chromatography/15 th GCxGC Symposium;

- Dr. Janusz Pawliszyn Medal 2016 for his contribution to the sample preparation area in Latin America, awarded at the Workshop on Recent Advances on Sample Preparation (WARPA); 
- Unicamp Inventors Award 2013 for the granted patent "Device for Solid Phase Micro-Extraction combined with dynamic headspace analysis (DHS-SPME)", granted by the Innovation Agency Inova Unicamp;

- Top Ten Chromatography, Mass Spectrometry and Lab Automation Papers Analytical Chemistry 2014, Chemical \& Engineering News American Chemical Society;

- Capes Thesis Award 2009 (area of Food Science) as coadvisor to Cláudia H. Kowalski doctoral thesis (advisor: Profa. Dra. Helena T. Godoy), award granted by the Brazilian Coordination for the Improvement of Higher Education Personnel (CAPES).

From 1999 to 2000, Fabio Augusto was a postdoc at the University of Waterloo (Canada) with the research group of Prof. Dr. Janusz Pawliszyn. In 2015, he held the Joliot Chair for invited foreign researchers from ESPCI (Ecole Supérieure de Physique et de Chimie Industrielles, Paris, France).

Fabio Augusto is currently full professor of the Department of Analytical Chemistry at IQ-Unicamp. To date, he has

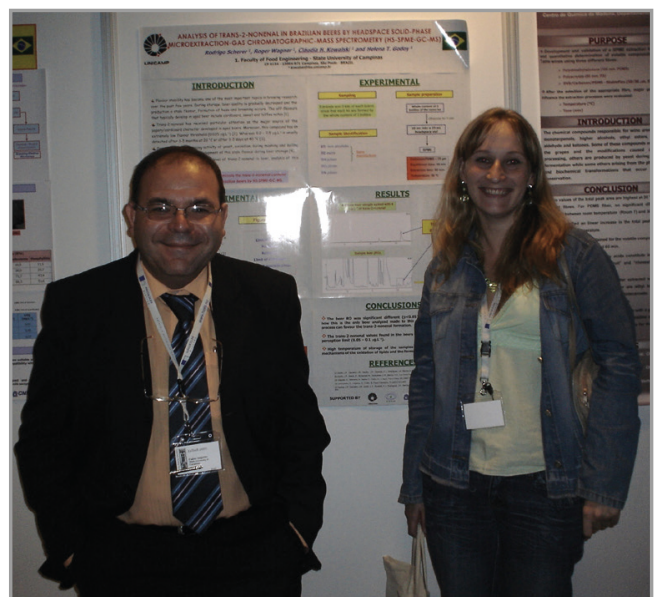

Fabio Augusto and Cláudia Kowalski at the $14^{\text {th }}$ International Symposium on Advances in Extraction Technologies (ExTech) in Alesund, Norway (2007). mentored over 60 postgraduate students, participated in over $\mathbf{4 0}$ thesis examining boards, and published over 200 papers. He works in the area of analytical separations, and his research is based on the development of comprehensive two-dimensional gas chromatography (GCxGC) instrumentation and methodologies combining this tool with extraction microtechniques and chemometrics for bioanalytical chemistry, and metabolomic, petroleomic, forensic, and food \& beverage analysis applications.

What early influences encouraged you to study science? Did you have any influencers, such as a teacher?

In fact, I don't remember any time in my life when I wanted to be something other than a "scientist". I'm from the first generation who saw man landing on the Moon, and I think that this left an impression on many kids and teens from the late 60 s through the mid-70s. To be a scientist was to participate in the future that we saw in movies and television series. It was a very different mood from what we have today, in which science is purposely discredited and undervalued by some groups and sectors of society. So, for me and for many people who are researchers or who work in the industrial sector today, the great incentive to become a scientist was this: being part of something that, in our minds, would be a great adventure and change the world.

When did you decide to go into the field of chemistry? What motivated you? How was the beginning of your career in chemistry?

Like many of my colleagues, my first contact with chemistry was through children's games, such as "The Little Chemist", which were very popular at that time. They were not cheap, and my family wasn't exactly wealthy (quite the opposite), but during my childhood I had a couple of these games. To the dismay of my parents, I started to say to everyone that I wanted to study chemistry. This seemed odd because being a chemist was not considered a "successful profession". But, eventually they accepted, and when I finished eighth grade in elementary school at the neighborhood school in São Bernardo do Campo, SP, I got a scholarship to attend a technical course in Industrial Chemistry from the former "Instituto de Ensino de São Caetano do Sul". This course was deficient in disciplines such as Portuguese and mathematics; however, we had some teachers with a good chemistry background and industry 
experience.

In mid-1981, the Rhodia Chemical Unit in Santo André opened an internship position for a technical trainee, lasting until December 1982. More than 60 people applied for this position, and after a selection process that lasted almost a month, I was selected. I started the internship in August 1981 at the Central Laboratory Service. This laboratory centralized all quality control of raw plant materials and finished

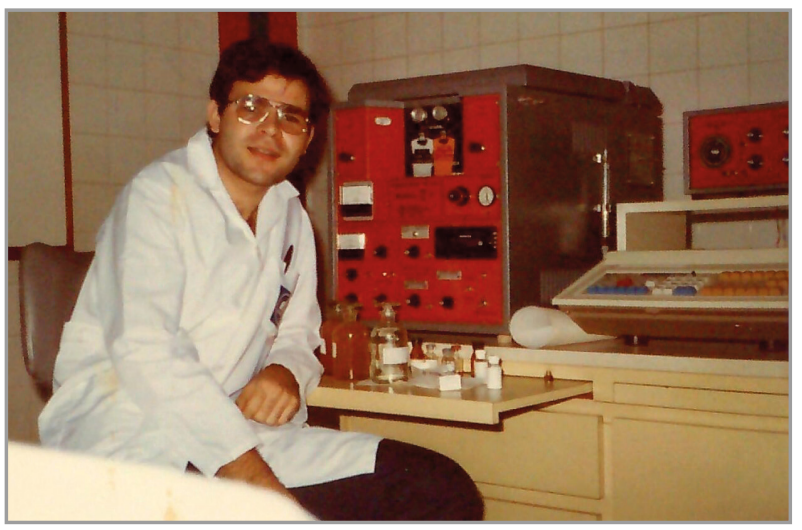

Fabio Augusto at Rhodia S.A. Gas Chromatography Lab in Santo André, SP, working on a chromatograph from "CG Instrumentos Científicos" (1982).

products and was in charge of monitoring boiler water quality and many other functions. The manager of the Central Laboratory Service was Dr. Claudio Puschel, who had a solid background in chemistry and was one of the best laboratory administrators I had ever met. He led me to work in the quality control of all available production lines, as well as assisting the senior laboratory chemist (Dejair Soria) in solving problems related to batches returned by customers for errors in analysis or developing methodologies for analysis of new products. That's when I came into contact with something very close to what would be analytical chemistry research, and I was sure that I had chosen the right career for myself. At the end of the internship, I was transferred to the Gas Chromatography Sector. The senior technician, João Luiz de Souza Carvalho, was a great teacher and encourager. This chemical unit of Rhodia had a very good instrument park at the time, and it was there that I started learning chromatography, working on the now legendary chromatographs of "CG Instrumentos Científicos."

In early 1982, I decided to take the university entrance exam only as an experience since there were still 6 months left for me to complete the technical course and one year left to finish my internship at Rhodia. I decided to take the entrance exam at Unicamp, in Campinas, SP, so that I would have a greater chance to pass to the second phase of the exam. To my astonishment, I was ranked sixth among the participants. This created a problem for my parents because they could not afford to support me outside the family home and without working. I decided to take time off from the university in 1982 to finish my internship and to save money. I started the chemistry course at Unicamp in 1983 and relied on financial help from family members.

At the end of the first year of the chemistry course at Unicamp, I sought out Prof. Antonio Luiz Pires Valente from the Analytical Chemistry Department at IQ-Unicamp. He was still doing his doctorate under Prof. Carol Collin's guidance, and he was a specialist in gas chromatography. Prof. Pires guided me through almost every undergraduate degree as a student of the Scientific Initiation program. He was a great connoisseur of analytical instrumentation and greatly appreciated teaching. When I graduated, I entered the master's degree and then the doctorate, always under the guidance of Prof. Pires. In 1992, I was hired at IQ-Unicamp.

\section{What has changed in the student profile, ambitions, and performance since the beginning of your career?}

There have been so many changes that it doesn't even seem like another generation; it's another world. The generation that is entering universities today is the first generation that has lived their entire lives with the ease of access to information provided by the Internet and smartphones. This profoundly influences their form of reasoning and world perspective. Our teaching uses models that worked for us and those who came before us, but they are no longer good for today's students. So, their performance is often poor, and I don't think it is entirely due to deficiency in their education (although this certainly plays a significant role). We need to change the way we teach science: I do not have the recipe for what 
must be done, but I am fully convinced that the current form of teaching has no future.

The profile of the newly graduated professionals is very different as well. Twenty or thirty years ago, it was very common for the highest achieving chemistry graduates to be strongly interested in working in the field of analytical chemistry, either in academic research or in private laboratories. Today, topics such as material science, energy, and biochemistry are much more attractive to recent graduates, both for job market opportunities and for being areas universally considered state-of-the-art in science.

\section{Could you briefly comment on recent developments in analytical chemistry, considering your contributions?}

As I mentioned above, the most active areas in cutting-edge developments are material science, new energy matrices, and biological chemistry. I believe this has changed the focus of modern analytical chemistry. For example, metabolomics, proteomics, and related areas demand analytical methods that are especially fast, automated and highly reliable, as well as able to handle the typical chemical species in samples from these fields, which include analytes traditionally regarded as problematic (large and highly polar molecules, labile substances, etc.). Thus, the various modalities of mass spectrometry, as well as their hyphenations with chromatographic systems and other techniques that allow ultrafast and minimal sample preparation, have been the target of many interesting developments. The availability of new materials has also been widely exploited by analytical chemists, such as in the increasing use of nanomaterials in sensors, electrodes, and as sorbent materials in various extraction formats. Another field that has developed quite sharply is that of portable and simplified instrumentation (often based on microfabricated components), notably for field analysis. In addition, many of these new analytical techniques and approaches result in large volumes of data that must be properly interpreted and manipulated. Increasingly, analytical chemistry is an information science, so the importance of using chemometric tools has become more and more pronounced. Many of these chemometric tools have become routine for modern analytical chemists. For some time, my point of view has been that the future of analytical chemistry research lies in the interfacing of these areas. Therefore, over the past few years, I have been working hard on combining multidimensional chromatography, fast extraction techniques such as SPME, and chemometric tools for multivariate analysis applied to highly complex samples. We have had very interesting results, with a reasonable impact on the literature and in the development of this area.

\section{What are your lines of research? You have published many scientific papers. Would you highlight} any?

Essentially, we operate in two major areas: development of systems and methodologies in comprehensive two-dimensional gas chromatography ( $\mathrm{GC} \times \mathrm{GC})$, for applications in petroleomics, food analysis, and plant and microbiological metabolomics, and microextraction techniques for chromatographic analysis. To date, we have published close to 120 articles in indexed journals. Although, in recent years, we have devoted ourselves much more to GCxGC. From the papers we have published, I find two of them more significant. As soon as I returned from my postdoctoral degree in Professor Janusz Pawliszyn's group at the University of Waterloo, Canada, I got financial resources and started my work with solid phase microextraction (SPME), which, at the time, was a relatively new technique, with many aspects to be explored. One interesting application of SPME is its use in the analysis of volatile food and beverage constituents associated with the aroma and quality of these products. At the time, I did

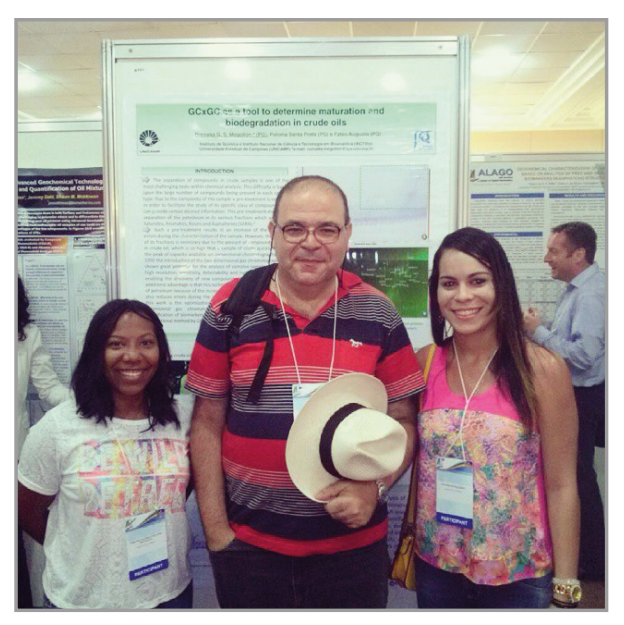

Poster presentation at the Congress of the Latin American Geochemistry Association, Búzios, RJ. From left: Noroska Mogollon, Fabio Augusto, and Paloma Prata (2015). 
not have my own GC-MS system, but I got Agilent to temporarily provide us with a GC-MS system for evaluation. We had this system in the lab for about a month. With the participation of a scientific initiation student and a master student, Eduardo Tada and Sandra Rivellino, respectively, we screened the composition of the volatile pulp fraction from a series of native fruits from Brazil. The chromatograph was used almost non-stop during the month while working on these analyses. Afterwards, we spent a few months processing the files acquired in the analyses, systematically identifying the detected compounds using public domain software since we did not have our own software. The results of this work were published in the Journal of Chromatography (J. Chromatogr. A, 2000, v. 873, p 117), and this was one of the first descriptions of a systematic application of SPME in the study of flavorings. For this reason, it has been (and still is) cited often in the literature.

Another paper that I consider equally significant was from our collaboration with my colleague, Prof. Ronei Poppi, who is one of the leading chemometrics specialists in Brazil. We developed a strategy to detect any kind of adulteration in gasoline using GCxGC and multivariate chromatogram processing. Our approach was to determine the purity of the samples by quantifying the base gasoline content. In adulterated samples, regardless of the nature of the adulterant, this content will be lower than that specified in the legislation. At the time, GCxGC was still a seldom explored tool, and this work (J. Chromatogr. A, 2008, v. 1201, p 176) was one of the first to demonstrate the enormous potential of combining this technique with multivariate data analysis strategies. The GCxGC system we employed was fully designed and built in our laboratory as part of the doctoral theses of Márcio Pozzobon Pedroso (now professor at the Federal University of Lavras, Lavras, MG) and Ernesto Correa Ferreira (who is a professor at the Federal Institute of Espírito Santo, Vitória, ES).

Do you keep yourself informed about the progress of research in chemistry? What is your opinion about the current progress of chemistry research in Brazil? What are the recent advances and challenges in scientific research in Brazil?

Overall, I believe there are some centers in Brazil where cutting-edge chemistry takes place, comparable with good research centers abroad. Approximately 10 chemistry postgraduate programs are rated 7 by CAPES, which means they are at an international level. Overall, research in Brazil, at least in universities and public institutions, has made a huge qualitative and quantitative leap in recent years. However, the current economic and financial situation of the country is calamitous, and, therefore, we are living something new: the National Council for Scientific and Technological Development (CNPq) will stop paying scholarships starting next September due to the exhaustion of its budget (unless new events occurs). This has been happening for some time with research project funding. Unfortunately, I have the feeling that this situation will continue for a long time, both because of the economic environment and also due to the unscientific environment that has established itself in important sectors of Brazilian society. The biggest scientific challenge in Brazil today is to survive this storm.

For you, what have been the most important recent achievements in the analytical chemistry research? What are the landmarks?

I believe that in the last 10 years, three important events have occurred in analytical chemistry: the "revival" of Raman spectroscopy as a routine analytical tool; the development of handheld, pocket-based analytical platforms recently implemented on smartphones; and the popularization of the combination between liquid chromatography and mass spectrometry to unveil the chemistry of biological systems. The first two were the result of the collaboration of many researchers, and I don't think it is possible to point out just one of them as being the most responsible. However, in the latter case, I think the big milestone was the 2002 Nobel Prize award to the inventor of the electrospray interface, John Fenn.

There are in Brazil and in the world several meetings on chemistry. To you, how important are these meetings to the scientific community? How do you see the development of national 


\section{chemistry meetings in Brazil?}

They are essential for science anywhere in the world, and especially in Brazil. Even today, with instant access to journals and the proliferation of alternative channels for scientific dissemination, personal interaction is indispensable for the emergence of new ideas and the discussion of trends and advances. In Brazil, this is the way researchers from smaller universities and research institutes can interact with scientists from the most advanced and up-to-date international centers.

In addition, as the number of researchers increases, the importance of regionalized or specific meetings grows. The National Analytical Chemistry Meetings (ENQA) are increasingly large events, attended by almost the entire analytical chemistry community in Brazil. Other meetings specializing in specific topics, such as COLACRO, have also grown in importance since they allow for direct contact of Brazilian students and researchers with colleagues from abroad; in these events, there is increasing participation of invited foreign researchers.

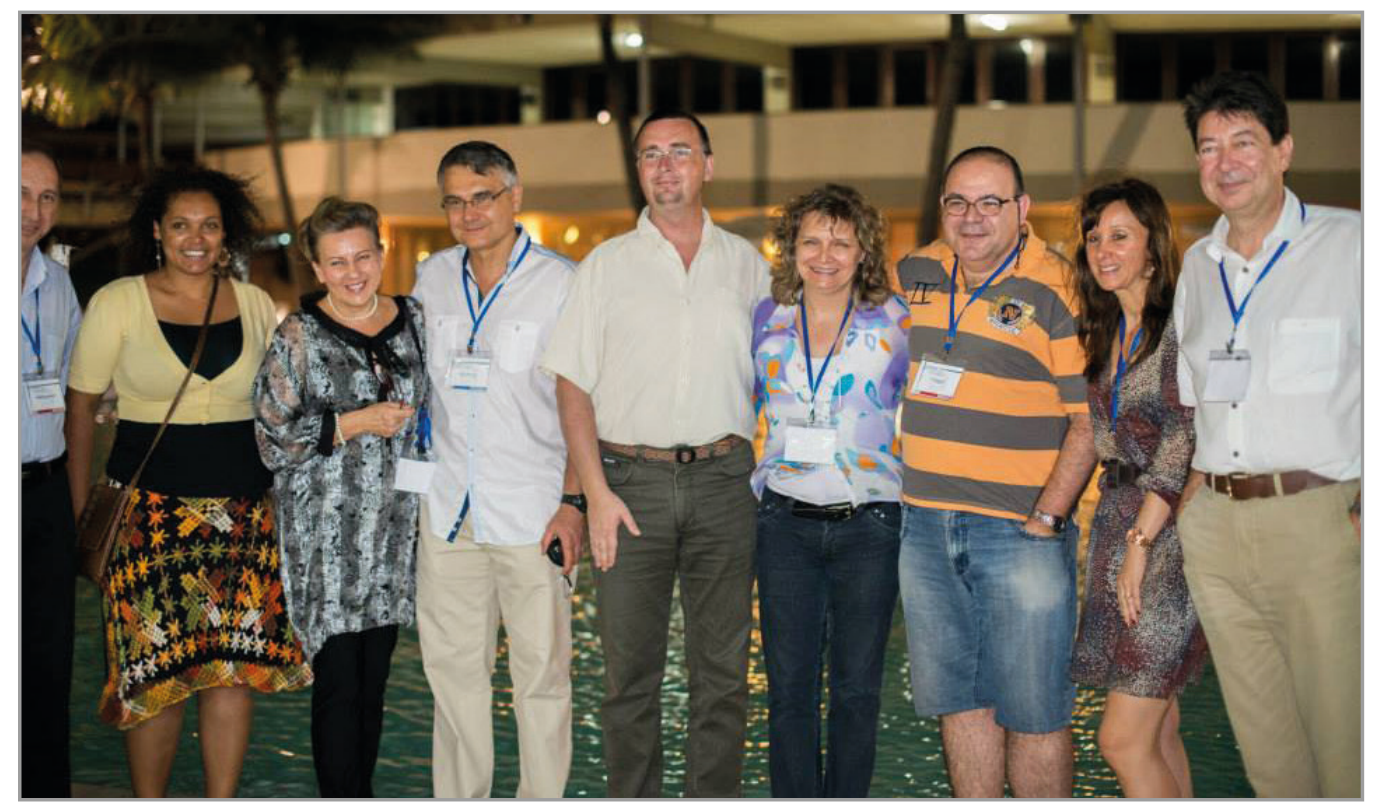

$15^{\text {th }}$ International Symposium on Advances in Extraction Technologies, ExTech 2013 in João Pessoa, PB, Brazil. Former members of Prof. Janusz Pawliszyn's group at the University of Waterloo, Canada. From left to right: Eduardo Carasek (Federal University of Santa Catarina, Brazil); Érica Silva (Federal University of São Paulo, Brazil); Elena Stashenko (Industrial University of Santander, Colombia); Janusz Pawliszyn; Zoltan Mester (National Research Council, Canada); Cláudia Zini (Federal University of Rio Grande do Sul, Brazil); Fabio Augusto; Maria Eugênia Queiroz (University of Sao Paulo, Brazil); and Tadeusz Goreki (University of Waterloo, Canada).

\section{You have already received some awards. What is it like to receive this kind of recognition? How did you feel about winning the "Ciola Medal"?}

For me, being chosen to receive the Ciola Medal was an honor and a pleasant surprise. I have been working with chromatography for 38 years, as a researcher, teacher, and technician, and this award represented to me the knowledge I was able to contribute to this area in Brazil. Obviously, nobody achieves anything on their own, and I think much of the merit comes from my students, both those I mentored in the masters and doctorate programs and those who attended undergraduate and postgraduate subjects I taught. They gave me the opportunity to grow professionally. I am absolutely sure that a good teacher learns more from his students than he teaches them. 


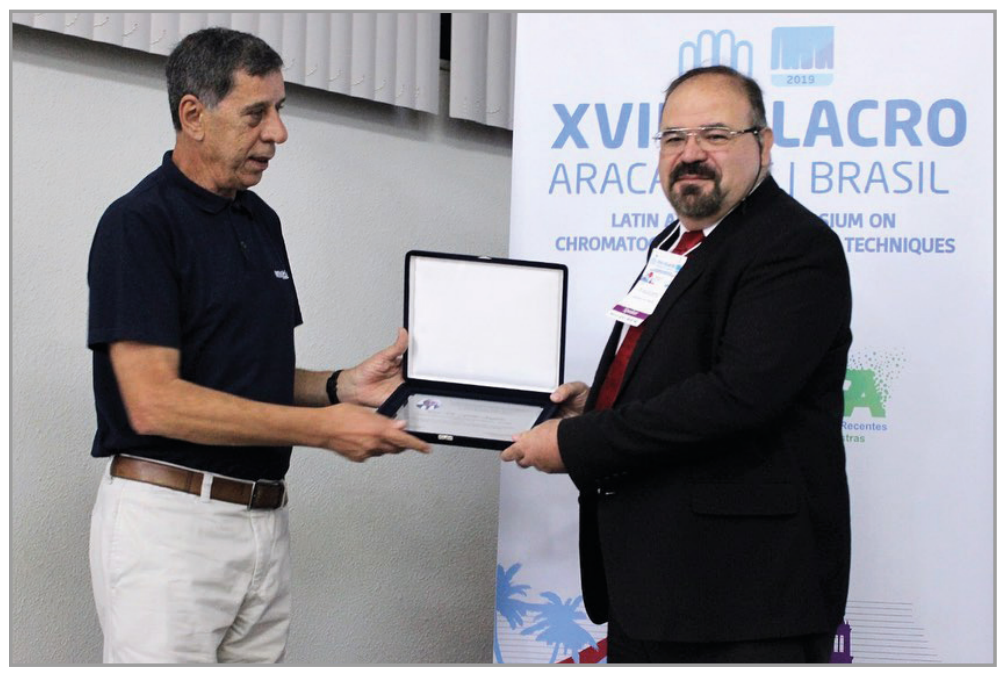

Luiz Bravo, director of the company Nova Analítica (left), handing the Ciola Medal to Fabio Augusto (right) at the opening ceremony of the XVII COLACRO in Aracaju, SE, Brazil (2019).

What is the importance of these awards in the development of science and new technologies?

I believe awards such as the Ciola Medal, regardless of its role in recognizing the importance of the recipient to the area, are also important to the new generation of scientists. They indicate researchers and scientists who have achieved successful careers, contributed to science, and are examples to follow.

For you, what is the importance of the funding support for the scientific development of Brazil?

Quality scientific research in Brazil is mainly done at public universities and federal and state research institutes, such as the National Institute of Pure and Applied Mathematics (IMPA), the National Institute of Amazonian Research (INPA), the National Institute of Space Research (INPE), Campinas Agronomic Institute (IAC), and the National Center for Research in Energy and Materials (CNPEM). Everywhere in the world, public funding is an essential source of research resources. However, in our country, for a variety of reasons, research funding depends almost exclusively on public funding agencies. The basis of our economy is the production of commodities, such as soybean, iron ore, and oil. Except for the oil industry, these are not sectors that create a high demand for new technologies, cutting edge knowledge, or innovative processes. Local companies in areas that might be interested in investing heavily in science and innovation are, largely, multinationals based abroad. Thus, unlike most of Europe and the United States, I do not see much potential for heavy private sector investment in research. One of the few exceptions has been the Brazilian Petroleum Corporation Petrobras (in any case, a state-owned company), which, both by necessity and legal demands, has invested heavily in research both internally and in universities. While the matrix of our industrial production and wealth generation is based on agricultural and mineral products, we will naturally depend on public investments for scientific development.

At the moment, the situation for scientific research in Brazil is one of decreasing investment. How do you see this situation, and what would you say to young researchers?

It seems to me that the present situation is a little worse than a simple occasional reduction in investments because of the unfavorable economic environment in the country. In recent years, in addition to experiencing a long-running financial crisis, which does not seem to be ending in the short term, (as I already mentioned, but not only in Brazil but worldwide), anti-scientificism has grown at an alarming rate. What was simply a manifestation of eccentric and localized niches is, in some cases, 
becoming a major trend, and even a determining factor in shaping environmental, scientific, and public health policies in countries of Brazil's size. Who would have thought 30 years ago that things like the belief that the earth is flat and intelligent design would be taken seriously by so many people? What I can say to those starting out in science today is this: As bad as the current picture may seem, don't give up. Although this crisis is the most serious l've ever seen, economically, morally, and ethically, it is certainly also part of a cyclical movement that has always existed and will exist. Crises are not eternal, and when the crisis is over we will need scientists and researchers more than ever.

What advice would you give to a young scientist who wants to pursue a career in Chromatography?

One should always keep in mind that analytical chemistry is essentially an applied science. It exists to solve real problems. Anyone wishing to make a significant contribution to the development of chromatography must be aware of the demands of industry, academia, and society. An analytical method or a new technique or device is only justified if it addresses a real problem. A new analytical concept or device developed and tested, if it generates only a scientific paper, later forgotten in a drawer, would have been nonsense and a waste of resources and time. To know where the relevant problems lie, we should always listen and interact with professionals in fields such as medicine, agronomy, food science, and environmental science, even though, in many cases, this is a naturally difficult dialogue.

\section{How would you like to be remembered?}

As relevant as a scientific paper or academic research may be, it will one day become obsolete. If I am remembered in the future, I hope it would be for having formed new professionals and researchers, whether they are chromatographers or not, and for having a positive impact on their careers.

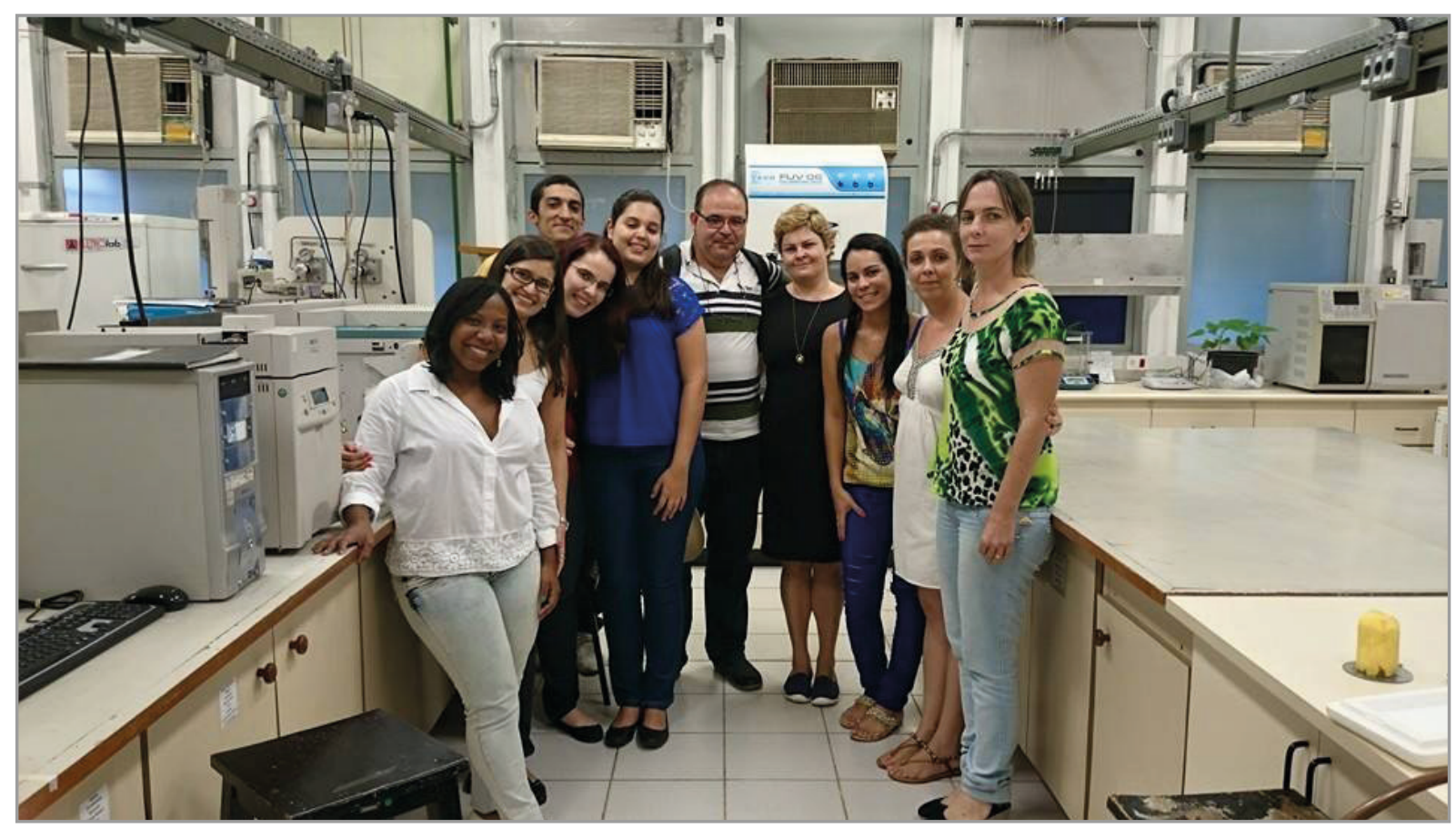

Fabio Augusto's research group at IQ-Unicamp in 2015. From left to right: Noroska Mogollon (now professor at the Amazon Regional University - Ikiam, Ecuador); Lucília Vilela (lab. technician); Mayra Fontes Furlan (senior chemist at "Kerry Aromas" and still in the group as a doctoral student); Jadson Reis (currently a PhD student at the Federal University of Espírito Santo); Bruna Sampaio (today, at Rhodia Solvay Group, Paulínia Industrial Unit, SP); Fabio Augusto and his wife, Rachel; Paloma Prata (postdoctoral student at the Federal University of São Carlos); Paula Lima (chemical analyst at "Valer Laboratórios"); and Sandra Rivellino (technical high school teacher). 